\title{
Application of Multimedia Technology in Vocabulary Learning for Engineering Students
}

\author{
https://doi.org/10.3991/ijet.v12i01.6153 \\ Xue Shi \\ Luoyang Institute of Science and Technology, Luoyang, China \\ xuewonder@aliyun.com
}

\begin{abstract}
The study of vocabulary is essential in learning a second language. The traditional way of foreign language learning only allows students to learn what the teacher chooses to teach. Knowledge is force-fed by the teacher to the students, but this way cannot meet the needs of the students and society. The development of multimedia technology meets the demands for new ways of teaching language. The purpose of this study is to test whether it is effective to use computer-assisted instruction (CAI) in individualized learning and whether multimedia CAI techniques can improve vocabulary learning and memory. According to analysis of the experimental data, CAI-supported vocabulary learning is more effective than traditional methods. The results show that, through CAI, knowledge can be learned faster and retained longer in the students' memory.
\end{abstract}

Keywords-multimedia technology, CIA, language learning

\section{$1 \quad$ Introduction}

Chinese students' difficulty in understanding English paragraphs or articles is primarily caused by their lack of sufficient vocabulary. Therefore, we are faced with the problem of how to improve students' ability to memorize English words quickly and retain these words in their long-term memory. These are some urgent issues that need to be resolved in order to achieve the maximum teaching result. In other words, mastering the right method and technique in vocabulary learning is crucial for successful learning of the English language. [1] Traditional English teaching normally follows the pattern of one-way teaching; i.e., the teacher force-feeds the knowledge to the students and the students passively receive the knowledge. In this process, the teacher takes full control of the classroom. Teaching materials are chosen by the teacher or prescribed by the school or the Education Department. Students play an insignificant role in the teaching process. Such a way of teaching can no longer meet the needs of the students and today's society. [2] 
It is known that learning is an active and highly individualized process. Constructivists clearly point out that learners must actively construct new knowledge based on their own individual experiences and understandings [3]. This constructivist model of learning is based on the concept that knowledge is produced by the individual learner rather than processed from information received from an external source. The theory of constructivism provides important guidance for current English language teaching. According to constructivism, a teacher should develop new models of teaching/learning that involves active participation of the students. With the wide-spread usage of computer technologies in many different fields, multimedia CAI, which refers to Computer Assisted Instruction involving the usage of multimedia equipment, is playing an increasing important role in English vocabulary teaching. [4]

CAI is a tool for initiative learning, collaboration, research and constructing new knowledge. In contrast to the traditional model of teaching in which the teacher passes knowledge to the students without regard to how well the knowledge is absorbed by the students. CAI focuses on assisting students to obtain new knowledge. [5]

\section{$2 \quad$ Literature Review}

The first computer serving the purpose of assisting teaching was produced in 1959 in the United States. Since then, theories relating to computer-assisted teaching proliferated in Western countries. Constructivists base their model on work by Jerome Bruner, Seymour Papert, Jean Piaget and Lev Vygotsky. According to their thought, education is an inseparable part of daily life. Through developmental exploration, students assume control of educational activities by making choices relating to their individual interests [6]. Students discover rules and concepts during the course of interactions in an environment that encourages the usage of problem-solving strategies, which in turn are developed while discovering how to think. The teacher learns along with the students and becomes a guide, a facilitator and a supportive partner in this educational process. Education is considered a guided tour of preparatory experiences in which students practice making decisions by simulating real-world situations [7]. The teacher becomes the facilitator of education by selecting the experiences that offer the appropriate practice for the students. In this way students construct their own knowledge and gain skills that will be needed in a future environment, which may be quite different from their present situation [8]. Students become the producer rather than the consumer of information. The teacher becomes the guide and facilitator of learning rather than the director of instruction. Teaching material is the object that is constructed by the students' own initiative rather than having the information forcefed by the teacher. CAI is an ideal tool for constructing new knowledge rather than the method where the teacher force-feeds knowledge into the students [9].

The function of the teacher, teaching material and CAI is to assist students to construct new knowledge. CAI can play a very important role in the learning environment. Much progress has been made in the development of CAI-related teaching theories based on constructivism. In recent years, however, the focus of many educational experts and institutions has shifted to applying the theories to teaching practices 
[10]. As a result, more efforts have been made to introduce computer-based multimedia technologies into traditional classrooms.[11]

\section{$3 \quad$ Methodology}

Based on the constructivist theory, students should be the center of courseware design. CAI can improve teaching in various ways, including creating rich learning environment, facilitating information resource design, assisting individualized learning and supposing learning effect evaluation [12]. The creation of a rich learning environment is crucial for successful vocabulary learning. The process of learning an English word involves not only memorizing the specific word, but more importantantly involvels students knowing how to use the word by learning it in the context of phrases, sentences or passages. With such considerations in mind, the experiment was designed according to the following four procedures.

\subsection{Hypothesis of the Study}

The experiments are designed to test the following hypotheses:

1. CAI-supported vocabulary learning is more effective than traditional vocabulary learning. Through CAI, knowledge can be learned faster and retained in the learners' memory for a longer period of time.

2. CAI-supported technology may better facilitate students' learning of the meaning of a specific word than the spelling of the word. Such a difference is not so obvious in traditional word teaching.

3. The students will be more interested in the CAI environment than the traditional classroom environment.

\subsection{Test Subjects}

Two classes in the School of Engineering, Class One and Class Four, both freshmen, are chosen as test subjects. Freshmen are chosen as the object of this experiment because they have just started college learning and for that reason, there are not such vast differences between their English levels as among students of higher grades. Therefore, there is less variance that needs to be considered in developing and evaluating the experiment.

Before the experiment, all students in Grade One took an English proficiency test. The average score of the above-referenced two classes are roughly the same. Therefore it can be assumed that the English levels of the students of these two classes are almost the same before the experiment. During the experiment, students of Class Four had classes in the multimedia CAI classroom five times every week, while students of Class One continued to have classes in the traditional way in an ordinary classroom environment. 
In order for the computer-assisted instruction to be successful, the students must be trained to use the computer for the purpose of learning new words. The students should be given the opportunity to familiarize themselves with the various application software and related techniques. The training need not take too long because most of the students already had computer courses in high school.

The results of the pre-course survey of Class Four are very optimistic. Students had high expectations of CIA language learning which could be concluded from the results shown in Table 1 that no one chose "strongly disagree" or "Disagree" to the statements. However, students in Class One did not have much confidence in course learning since $10 \%$ students had negative opinions; i.e., $2 \%$ chose "Strongly disagree" and $8 \%$ chose "disagree".

Table 1. Expectations for the course from students in Class Four

\begin{tabular}{|l|c|c|c|c|c|}
\hline & $\mathbf{1}$ & $\mathbf{2}$ & $\mathbf{3}$ & $\mathbf{4}$ & $\mathbf{5}$ \\
\hline 1. To better memorize the vocabulary & 0 & 0 & $29 \%$ & $32 \%$ & $39 \%$ \\
\hline 2. To have fun while learning & 0 & 0 & $15 \%$ & $27 \%$ & $58 \%$ \\
\hline 3. To pick up something new & 0 & 0 & $30 \%$ & $31 \%$ & $40 \%$ \\
\hline
\end{tabular}

Table 2. Expectations for the course from students in Class One

\begin{tabular}{|l|c|c|c|c|c|}
\hline & $\mathbf{1}$ & $\mathbf{2}$ & $\mathbf{3}$ & $\mathbf{4}$ & $\mathbf{5}$ \\
\hline 1. To better learn the course material & $2 \%$ & $8 \%$ & $32 \%$ & $30 \%$ & $28 \%$ \\
\hline 2. To better bond with teachers & 0 & $2 \%$ & $33 \%$ & $31 \%$ & $34 \%$ \\
\hline 3. To cultivate relationships with colleagues & 0 & 0 & $19 \%$ & $25 \%$ & $56 \%$ \\
\hline
\end{tabular}

1 Strongly disagree 2 Disagree 3 Neither agree or disagree 4 Agree 5 Strongly agree

\subsection{Learning materials}

Learning materials were from the textbook and additional materials selected by the teacher. There were about twenty English words in each unit of the textbook. The teacher provided an additional twenty words related to those words in the textbook. So the students must learn about forty English words in each unit per week. The experiment lasted for one semester (from September, 2015 to January, 2016), during which period of time the student can learn around six hundred words. The learning units consisted of different types of words, with varying lengthes and levels of difficulty.

The students of Class Four learned these words in the multimedia CAI classroom. The learning materials were prepared and presented with the help of computers. Students can read the words and their meanings as well as see the visual images relating the words and hear the pronunciation at the same time. By clicking the hotlink besides the words, students can immediately access some examples showing the usage of these words. Such technological assistance was not provided to students in Class One. 
Instead, students in Class One were arranged in the traditional classroom environment and presented with printed materials only.

In preparing the CAI courseware, the teacher must process the words using various computer software. The final product, as shown in Figures 1 to 4, allows the students to see the words on the screen accompanied by pictures or videos. They can also hear the standard American English pronunciation and read sentences and paragraphs containing the words by clicking the hotlinks.

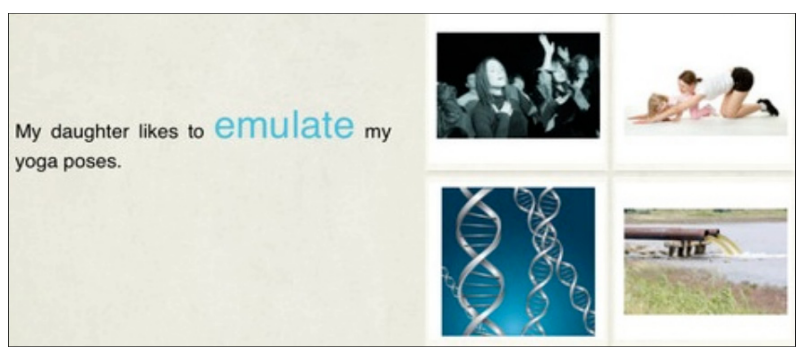

Fig. 1. Sentences with pictures

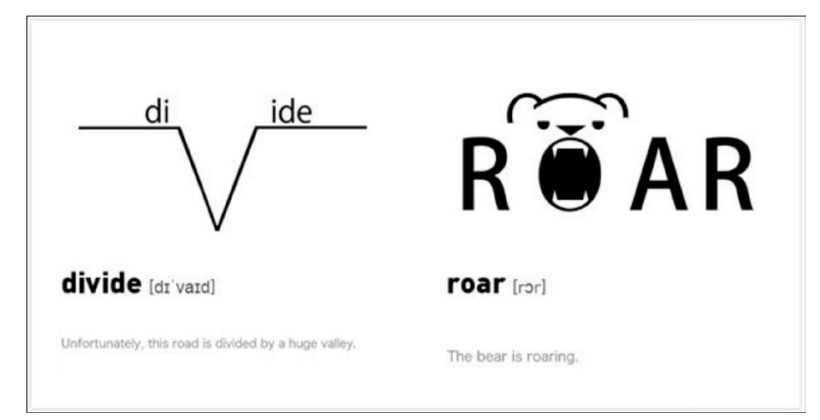

Fig. 2. Visualized pictures for meanings of words

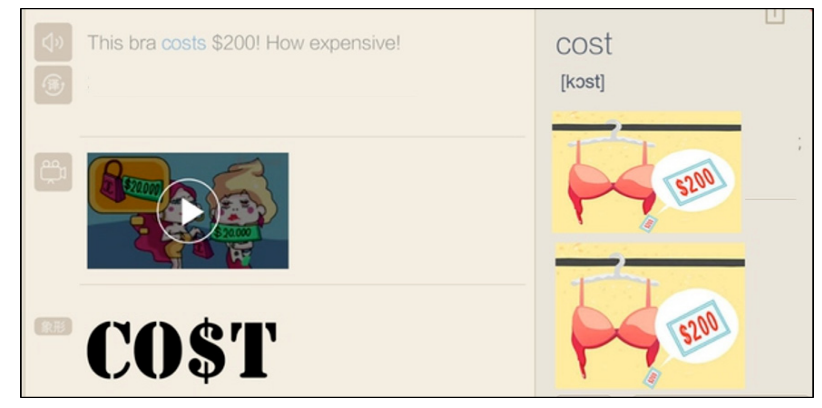

Fig. 3. Words memory with the aid of video 


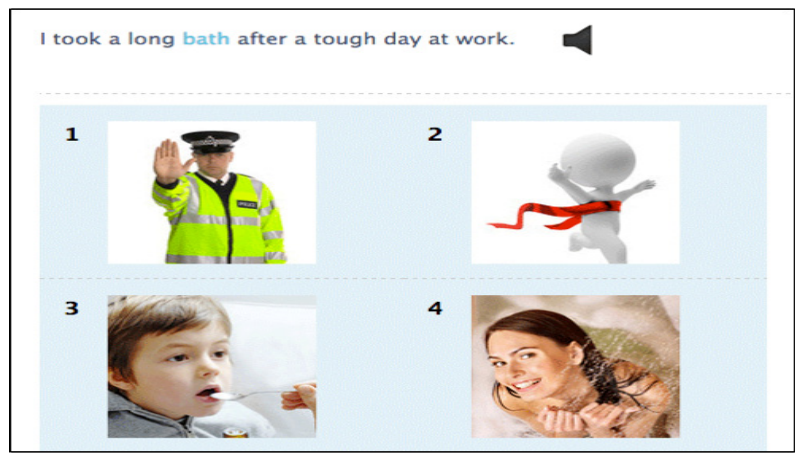

Fig. 4. Visualized pictures for choices questions

The typical learning steps in the multimedia CAI classroom is presented in Figure 5. Firstly, the teacher shows the students the teaching demands of the lesson. At this time, the teacher can control all the students' screens with the remote control function so that every student can listen carefully. Then the students can learn the materials actively. After that, the control messages are broadcast while the students can individually control their own computer. They click the words of the list on the homepage and begin to learn the words. Before the class is over, the students will have a quiz to evaluate the effect of this lesson. The quiz is inputted in a computer testing system. The teacher and the students can get the result of the test immediately. Moreover the result can be analyzed by the test system automatically. The teacher can know the effect that the lesson has had on the students. This makes the teacher's work more effective. The computer can also provide immediate feedback to students. The students can immediately find out where they made mistakes. Feedback can help students to better grasp the knowledge.

In the lesson, the students are the center of learning. They follow the teaching goal and work at their own pace. The teacher is a guide to give appropriate instructions to the students.

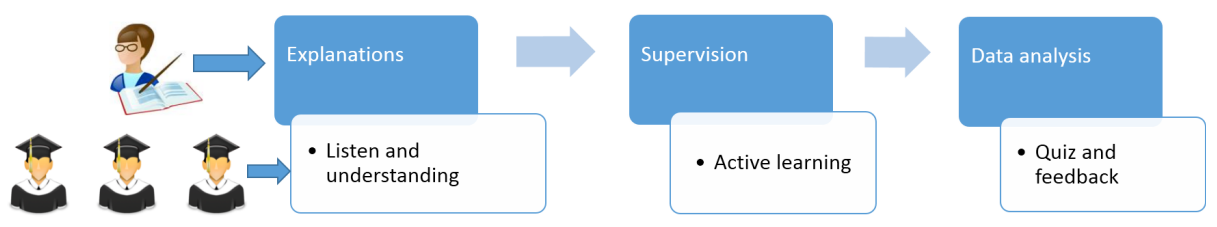

Fig. 5. Typical teaching/learning steps

\subsection{Tests and data collection}

Throughout the semester, students were given four tests. The first one was taken before the experiment. The second and third tests were taken during the experiment, and the fourth one was taken toward the end of the experiment when the students had 
studied about fourteen units consisting of about 600 English words. After each test, the teacher collected and analyzed the test data.

In order to better understand the test data, standard deviation (SD) is used as a measure the dispersion or variation in a distribution. It equals to the square root of the arithmetic mean of the squares of the deviations from the arithmetic mean.

Standard deviation is used to show how tightly all the various examples are clustered around the mean in a set of data. For example, according to the test scores, if SD is relatively small, it shows that the level of all the students in the class is similar. However, if the average score is high, it shows the students in general have a good understanding of what they have learned. If the average score is low, it shows they have not mastered the new knowledge. If SD is a relatively greater figure, it suggests that there are vast differences between the English levels of the students and that the distinction between the top students and low-level students is more obvious.

\section{$4 \quad$ Results and Discussion}

As mentioned above, students had four tests during the semester. The type of the test was multinomial choices. Each test consisted of 50 multiple choice questions, among which the first 25 questions were designed to test the students' ability to understand the words, and the remaining 25 questions were focused on testing their spelling skills. The questions were arranged randomly. Each question weighted an equal two points, meaning that if one got every question correct, that student would get a full score of 100. After the test, the student's score for each part was calculated and then the two scores were added together to produce the final score. After each test, the teacher collected and analyzed the test result. Figure 6 shows the results of the average score and Figure 7 shows the SD value. The difference between Class One, who had lectures in a traditional classroom setting, and Class Four, who had lectures in multimedia CAI classroom, highlights the significance.

\subsection{Analysis of the Results}

As can be seen in Figure 6, the average scores of Class Four are higher than those of Class One in the last three tests, and the distinction between the two classes is increasing gradually. This shows that the students of Class Four, who studied in the CAI-supported learning environment, made greater progress than the students of Class One, who studied in the traditional learning environment. According to the average scores of meaning and spelling, the students of the two classes all did meaning exercises better than spelling exercises. The distinction of the two classes is not obvious in each test. So it can be concluded that the two different ways of learning both allow students to better memorize the meaning of the English words rather than their spelling.

While the average score is a good indicator of the overall English level of the class, it cannot show the information of each student accurately. The SD value can achieve this, as shown in Figure 7. The SDs of Class Four became increasingly smaller in the 
last three tests, and such change is more obvious in the previous two tests. It reflects the difference among the students in Class Four becoming increasingly smaller. Students, especially those who were weak in vocabulary learning, made great progress during the experiment. However, the SD of Class One had changed very little in the four tests, indicating that there is no significant change in the differences in the English levels among the students. The reason is that students were still passively accepting the learning materials and they did not actively participate in the learning, which shows that the traditional way of teaching cannot meet the needs of the students.

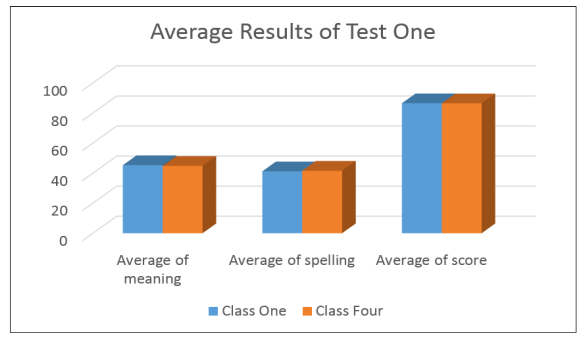

Average Results of Test Three

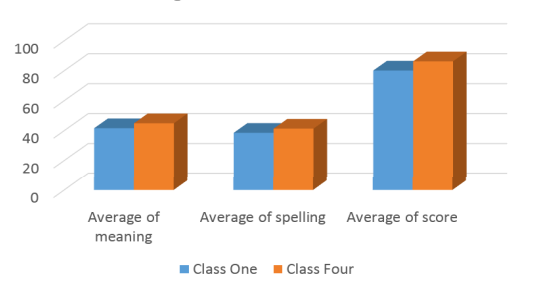

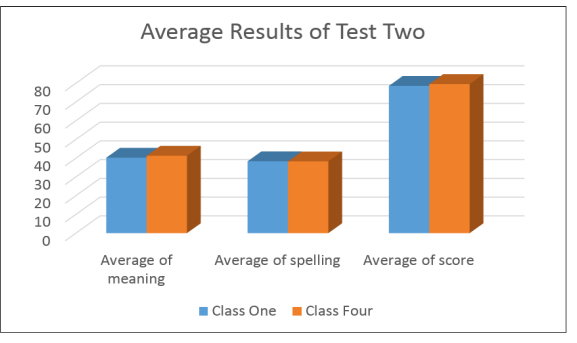

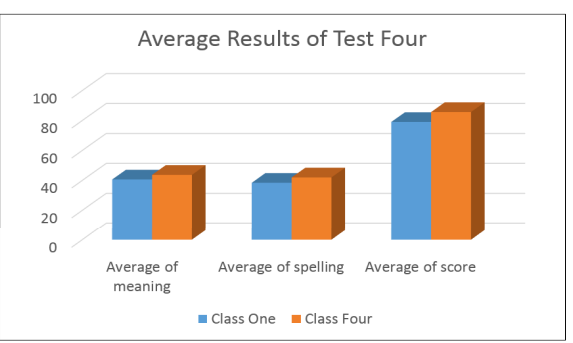

Fig. 6. Average results of the four tests
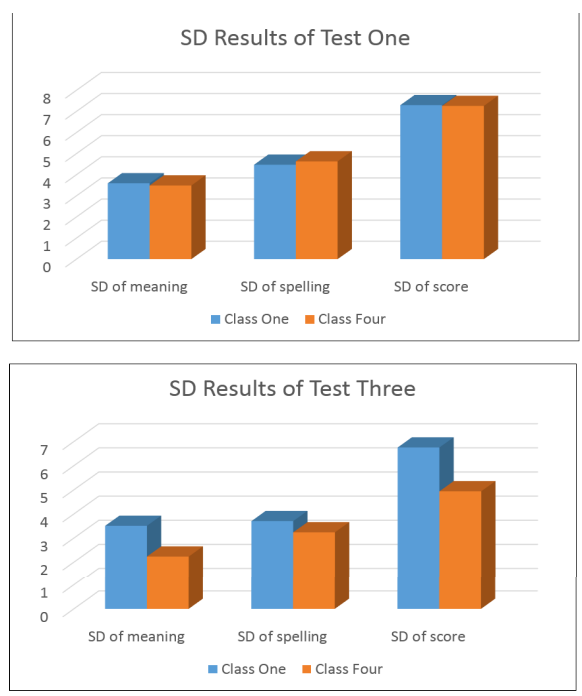
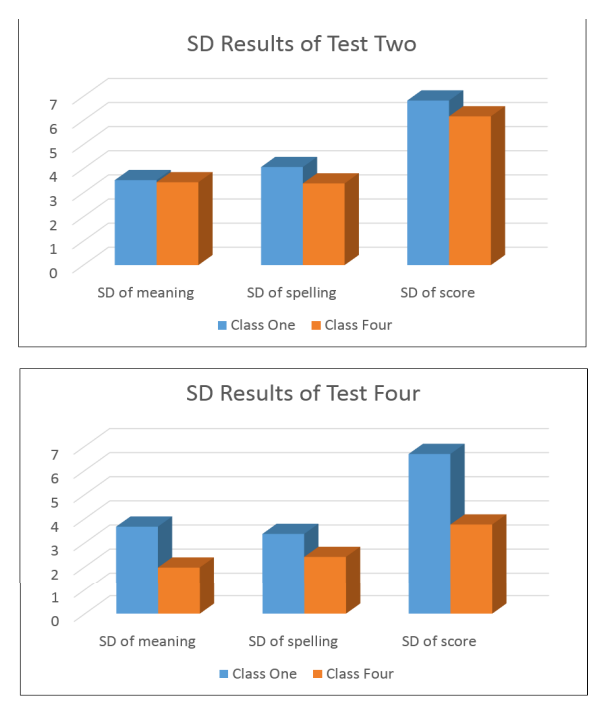

Fig. 7. SD results of the four tests 


\subsection{The Effect of the Experiment}

From the comparison of the averages scores of the two classes in the four tests, the experiment shows that the effect of CAI-supported words learning is more effective than traditional vocabulary learning. Through CAI, knowledge can be learned faster and retained longer [13]. Therefore the first hypothesis is tested to be true. CAI does help students actively construct new knowledge based on their individual experiences and understandings [14].

In terms of the comparison of the SDs of the two classes in the four tests, it shows that the difference among the students in Class Four becomes increasingly smaller. The students who were weak in learning made especially large progress. The effect of the experiment on them is more obvious. So the third hypothesis is confirmed.

The analysis also suggests that in terms of the effects of learning a word's meaning and its spelling, the two classes show a similar pattern. The students of both classes can better memorize a word's meaning than its spelling. According to the comparison of the SDs and the average scores of meaning and spelling, the distinction of the two classes is not obvious in each test. So it can be concluded that the two different ways of learning allow students to better memorize the meaning of the English words rather than their spelling. Such a result contradicts with the second hypothesis, which assumes that CAI-supported technology can better facilitate students' learning of words' meaning than the traditional teaching method.

As is suggested by the students, this kind of teaching method should extent to other courses related to English language learning.

Table 3. Results of the post-course questionnaire

\begin{tabular}{|l|c|c|c|c|c|}
\hline \multicolumn{1}{|c|}{ Questions } & $\mathbf{1}$ & $\mathbf{2}$ & $\mathbf{3}$ & $\mathbf{4}$ & $\mathbf{5}$ \\
\hline A. It made me better learn the course. & 0 & 0 & $2 \%$ & $39 \%$ & $59 \%$ \\
\hline B. I enjoy this form of learning. & 0 & 0 & $3 \%$ & $30 \%$ & $67 \%$ \\
\hline C. I will recommend it to other students. & 0 & 0 & $5 \%$ & $18 \%$ & $77 \%$ \\
\hline D. I expect to learn under this model more. & 0 & 0 & $4 \%$ & $36 \%$ & $60 \%$ \\
\hline
\end{tabular}

1 Strongly disagree 2 Disagree 3 Neither agree or disagree 4 Agree 5 Strongly agree

Based on the post-course questionnaire, which is shown in Table 3, students are satisfied and interested in the CAI-supported learning. To make the courseware more effective, one must keep in mind that the students' internal responses to stimuli are closely related to the effectiveness of learning. If computer software can keep the students alert and motivated, it normally will be more effective than those that cannot achieve such results. That is why teachers must try to create multiple sensual stimuli to gain students' attention and keep them interested. A combination of different events or activities will be more interesting than one or two continuously repeated actions. Variety can be achieved by offering, for example, interaction through the tactile response of typing on the keyboard, using different sounds, bright colors, and interesting graphics. In addition, communication among the students and between teachers and students may help to make the class more interesting. 


\section{Conclusions}

Despite of the high costs of equipment and staff training as well as increasing workload for teachers, the advantages of CAI-supported individualized learning design are obvious.

Firstly, CAI has the potential to enhance individualized instruction without requiring an increase in the number of teachers.

Secondly, through its usage of text, sound, graphics, animation and multimedia, CAI is ideally suited to present a very rich learning environment. Computers can help students' learning because they present materials in a better way than textbooks, and they keep records for feedbacks and analysis.

Thirdly, CAI encourages active learning, uses the results of previous learning, promotes learning with comprehension, and allows students to see their progress [15].

Furthermore, it is necessary to continue the study of the CAI-supported learning, and this kind of learning should be extended into middle schools and high schools so that an increasing number of students can benefit from the advanced technology. The multimedia CAI technology has changed the methods of learning and teaching. In the rich environment provided by the multimedia CAI technology, the learning procedure becomes easier and more interesting, and students can better grasp the knowledge they have learned.

\section{References}

1. Aiqin Liu, "An Exploratory Study on Application of Multimedia Technology in College English Teaching and Learning", Physics Procedia, 2012,vol. 24, no.24,pp. 2334-2338. https://doi.org/10.1016/j.phpro.2012.02.346

2. Xinguang Shao, Xiuqin Xu, "Cognitive Effects of Grammatical Metaphor on English Reading in Multi-media Setting”, Media in Foreign Language Instruction, 2015,vol.12. no.1, pp.57-61.

3. Jiliang Wang, "The Construction of Constructivist Learning Environment", Media in Foreign Language Instruction, 2004, vol.12, no. 4, pp.8-12.

4. Yang Xiaohui, "Status quo and Future: Multimedia Application in Higher Education", $A d$ vanced Materials Research, 2010, vol.24, no. 22, pp. 1023-1027. https://doi.org/10.4028/www.scientific.net/AMR.121-122.1023

5. Teoh, Belinda S. P., Neo, Tse-Kian, "Innovative Teaching: Using Multimedia to Engage Students in Interactive Learning in Higher Education, 7th International Conference on Information Technology Based Higher Education and Training”, ITHET, 2006,vol.1,no. 1, pp. 329-337.

6. Jonassen, D. H., "Thinking Technology: Toward a Constructivist Design Model”, Educational Technology, 1994, vol. 12, no.3, pp.34-37.

7. Jiao Xuhua, Chen Cheng, "Thoughts on Application of Multimedia in Education, Proceedings of the 2011 International Conference on Future Computer Science and Education", ICFCSE, 2011,vol. 1, no.1, pp.591-594.

8. Puangtong Petchtone, "The Development of Instructional Model Integrated with Thinking Skills and Knowledge Constructivism for Undergraduate Students", Procedia-Social and 
Paper-Application of Multimedia Technology in Vocabulary Learning for Engineering Students

Behavioral Sciences, 2014, vol. 215, no.116, pp.4283-4286. https://doi.org/10.1016/j.sbspro.2014.01.932

9. Eskicioglu, A.M., Kopec, D., "The Ideal Multimedia-enabled Classroom: Perspectives from Psychology, Education and Information Science", ASEE Annual Conference Proceedings, 2003, vol.1, no. 1, pp. 11985-12002.

10. Nuket Gunduz, Cigdem Hursen, "Constructivism in Teaching and Learning; Content Analysis Evaluation", Procedia - Social and Behavioral Sciences, 2015, vol. 215, no.191, pp.526-533. https://doi.org/10.1016/j.sbspro.2015.04.640

11. Le Xiang Yi, "A Tentative Exploration on the Use of Multi-media in College English Education", AASRI Procedia, 2012, vol.12, no.1, pp. 282-286. https://doi.org/10.1016/j.aasri.2012.06.043

12. Liu Zhengxi, "Analysis of Positive Effect of Computer Multimedia Technology on English Education”, WIT Transactions on Engineering Sciences, 2014, vol.87, no.87, pp. 935-940. https://doi.org/10.2495/AMITP131131

13. Lingfang Fu, Jianding Yang, "Teaching and Learning Model Based on Multimedia and Network", Foreign Languages and Their Teaching, 2007, vol. 12, no.10, pp. 36-38.

14. Emily Ely, Michael J. Kennedy, Paige C. Pullen, Mira Cole Williams, Shanna Eisner Hirsch, "Improving Instruction of Future Teachers: A Multimedia Approach That Supports Implementation of Evidence-based Vocabulary Practices", Teaching and Teacher Education, 2014, vol. 24, no.24, pp. 35-43. https://doi.org/10.1016/j.tate.2014.07.012

15. Kadir Kozan, Gülcan Erçetin, Jennifer C. Richardson, "Input Modality and Working Memory: Effects on Second Language Text Comprehension in a Multimedia Learning Environment", System, 2015, vol.55, no. 55, pp. 63-73. https://doi.org/10.1016/j.system.2015.09.001

\section{Author}

Xue Shi is a lecturer in School of Foreign Languages, Luoyang Institute of Science and Technology, Luoyang, 471023, China. Her research interests include the applied linguistics, English language teaching, etc. (email: xuewonder @aliyun.com)

Submitted 17 August 2016. Published as resubmitted by the author 10 October 2016. 